\title{
Angiotensin-Converting Enzyme Inhibition Alters the Inflammatory and Fibrinolytic Response to Cardiopulmonary Bypass in Children
}

\author{
Gregory A. Fleming, M.D., M.S.C.I., Frederic T. Billings IV, M.D., M.S.C.I., Tom M. Klein, \\ B.S., C.C.P., David P. Bichell, M.D., Karla G. Christian, M.D., and Mias Pretorius, M.B.Ch.B., \\ M.S.C.I. \\ Division of Pediatric Cardiology, Department of Pediatrics (GAF);Department of Anesthesiology \\ (FTB, MP); Division of Pediatric Cardiac Surgery, Department of Cardiac Surgery (TK, DPB, \\ KGC), and Division of Clinical Pharmacology, Department of Medicine (MP), Vanderbilt University \\ Medical School, Nashville, TN
}

\section{Abstract}

Objective-Many children with a congenital heart defect undergo surgical correction requiring cardiopulmonary bypass (CPB). One sixth of these patients take an angiotensin-converting enzyme inhibitor (ACEi) for heart failure treatment. The effect of ACE inhibition on the fibrinolytic and inflammatory response in children undergoing CPB is unknown. In adults, ACE inhibition attenuates the increase in plasminogen activator inhibitor-1 (PAI-1) following CPB whereas the effect on the interleukin (IL)-6 response is uncertain. This study tests the hypothesis that preoperative ACE inhibition attenuates postoperative PAI-1 and IL-6 expression following $\mathrm{CPB}$ in children.

Design-Single center prospective randomized non-blinded study.

Setting-University-affiliated pediatric hospital.

Patients-Children undergoing elective surgical correction of a congenital heart defect requiring $\mathrm{CPB}$ and taking an ACEi.

Interventions-Children were randomized to continue ACEi until the morning of surgery (ACEi group, $\mathrm{N}=11$ ) or to discontinue therapy 72 hours prior to surgery (No ACEi group, $\mathrm{N}=9$ ).

Measurement and Main Results_Blood samples were collected at baseline before CPB, at $30 \mathrm{~min}$ of CPB, upon arrival to the ICU, and on postoperative day 1 (POD1). Baseline bradykinin concentrations were significantly higher and ACE activity significantly lower in the ACEi group compared to the no ACEi group ( $\mathrm{P}=0.04$ and $\mathrm{P}=0.001$ respectively). PAI-1 antigen increased $15-$ fold following CPB and peaked on POD1 (from $4.6 \pm 1.2$ to $67.7 \pm 9.5 \mathrm{ng} / \mathrm{ml} ; \mathrm{P}<0.001$ ). POD1 PAI-1 antigen correlated significantly with $\mathrm{CPB}$ time $\left(\mathrm{r}^{2}=0.40, \mathrm{P}=0.03\right)$ and was significantly lower in the ACEi group compared to the no ACEi group ( $\mathrm{P}=0.03)$. The pro-inflammatory markers IL-6 and IL-8, as well as the anti-inflammatory marker IL-10, increased significantly following CPB (all P<0.001). IL-6 concentrations were significantly higher in the ACEi group

Correspondence: Mias Pretorius, MBChB, MSCI, 561 PRB, Vanderbilt University Medical Center, Nashville, TN 37232, Fax: (615) 343-2551, Phone: (615) 343-0665, mias.pretorius@ vanderbilt.edu.

Reprints: No reprints will be ordered.

Clinical Trial Registration Information: NCT00848250

Conflict of interest

None 
following $\mathrm{CPB}(\mathrm{P}=0.02)$ even after controlling for potential confounding factors such as age, $\mathrm{CPB}$ time and transfusion volume.

Conclusion-ACE inhibition attenuates the increase in postoperative PAI-1 but enhances the IL-6 response in children undergoing CPB.

\section{Keywords}

angiotensin converting enzyme; plasminogen activator; interleukin; pediatric surgery; acute kidney injury; cardiopulmonary bypass

\section{Introduction}

Many children with congenital heart defects require cardiac surgery with the assistance of cardiopulmonary bypass (CPB), and approximately $15 \%$ of these children take an angiotensin-converting enzyme inhibitor (ACEi) for heart failure treatment (1). CPB activates inflammation, coagulation and fibrinolysis, resulting in an increase in plasminogen activator inhibitor-1 (PAI-1) and interleukin (IL)-6 concentrations in the postoperative period (2-4). PAI-1 inhibits fibrinolysis by forming a complex with tissue-type plasminogen activator (t-PA), thereby preventing its interaction with plasminogen. Increased PAI-1 concentrations have been associated with early vein graft failure in adults (5) and central venous thrombosis in children after cardiac surgery (6). Systemic inflammation, as measured by IL- 6 and IL- 8 concentrations, is associated with the development of acute kidney injury (AKI) and prolonged ventilation in children undergoing cardiac surgery (7).

Angiotensin-converting enzyme (ACE) inhibition decreases the formation of angiotensin (Ang) II, a potent stimulus of PAI-1 and IL-6 expression, $(8,9)$ and decreases the degradation of bradykinin, a potent stimulus of endothelial t-PA release and IL-6 expression (10-12). In adult patients undergoing CPB, preoperative ACE inhibition attenuates the increase in postoperative PAI-1, (2) however the effect of ACE inhibition on the postoperative inflammatory response is uncertain. Some studies found that ACE inhibition blunts the inflammatory response $(13,14)$ whereas other studies found no effect $(15)$. The effect of ACE inhibition on the fibrinolytic and inflammatory response following CPB is not known in children.

The purpose of this study was to test the hypothesis that preoperative ACE inhibition attenuates the postoperative PAI- 1 and IL-6 response in children undergoing cardiac surgery requiring $\mathrm{CPB}$.

\section{Methods}

Twenty (13 male and 7 female) children participated in the study (ClinicalTrials.gov Identifier: NCT00848250). This study was approved by the Vanderbilt University Institutional Review Board for Research on Human Patients and conducted according to the Declaration of Helsinki. A legal guardian of all patients provided written informed consent, and patients greater than 7 years of age additionally signed an assent form. Patients were eligible for the study if they were: 1) less than 17 years of age, 2) undergoing elective cardiac surgery, and 3) taking an ACEi preoperatively. Patients were excluded for the following reasons: 1) discontinuation of ACEi was deemed unsafe by their primary cardiologist, 2) inability of the patient's legal guardian to understand the nature, scope, and possible consequences of the study, 3) pregnancy as determined by standard of care screening procedures, 4) weight less than $3.5 \mathrm{~kg}, 5$ ) inability of the patient to comply with the protocol (i.e., children in whom it was deemed unsafe to have the extra blood draws, and 
children who were thought to be noncompliant with their medications), and 6) completion of surgery without the use of CPB.

\section{Patients}

Twenty-nine patients were found eligible and were approached for inclusion in the study. Eight patients refused participation. Twenty-one patients consented, but one patient was excluded after it was decided to perform their surgery without CPB. Twenty patients completed the study and were included in the final analysis.

\section{Protocol}

Patients were randomized at the time of consent to either 1) discontinue ACEi use 72 hours before surgery, or 2) continue ACEi use until the day of surgery. There were no preoperative complications observed in patients who were randomized to stop their ACE inhibitor. Randomization was non-blinded to both study personnel and patients. Baseline lab assessment, (hemoglobin, hematocrit, white blood count, platelet count, potassium, BUN, and creatinine) and baseline vital signs (height, weight, blood pressure, heart rate, and oxygen saturation by pulse oximetry) were obtained during the preoperative visit.

\section{Anesthesia and cardiopulmonary bypass}

Patients were premedicated with oral midazolam $(0.5-0.7 \mathrm{mg} / \mathrm{kg})$ prior to surgery. General endotracheal anesthesia was induced with a mixture of inhaled sevoflurane, nitrous oxide, and oxygen, and maintained with isoflurane, fentanyl, and pancuronium $(0.1-0.5 \mathrm{mg} / \mathrm{kg})$. Continuous monitoring included 5-lead electrocardiography, pulse oximetry, end-expiratory $\mathrm{CO}_{2}$, invasive arterial blood pressure (radial, brachial, or femoral artery), central venous pressure (internal jugular or subclavian vein), rectal temperature, and cerebral oximetry near-infrared spectrophotometry (Somanetics, INVOS; Troy, MI). Methylprednisolone (7 $\mathrm{mg} / \mathrm{kg}$ ) was administered intravenously to all patients prior to the initiation of CPB. Aminocaproic acid (antifibrinolytic) was given intraoperatively at the discretion of the attending anesthesiologist.

CPB was achieved in all patients with aortic arterial and bicaval venous cannulation. The extracorporeal circuit included a System One heart-lung machine with occlusive arterial roller-head (Terumo Cardiovascular Systems Corporation, Ann Arbor, MI), biocompatible $\mathrm{X}$-coated tubing pack, hollow fiber oxygenator and hard-shell venous reservoir (Terumo Cardiovascular Systems Corporation, Ann Arbor, MI), hemoconcentrator, and continuous in-line monitoring (Terumo Cardiovascular Systems Corporation, Ann Arbor, MI). The circuit was primed with a mixture of albumin, packed red blood cells, fresh frozen plasma and plasmalyte-A. After pre-bypass ultrafiltration (pre-BUF) of this mixture, mannitol, sodium bicarbonate, calcium chloride, and heparin were added to the washed circuit prime in doses adjusted for body surface area. Perfusion flow rates during normothermia were $100-175 \mathrm{ml} / \mathrm{kg} / \mathrm{min}$ and pump flow was gradually reduced during cooling per standard protocol. Moderate hypothermia $\left(34-35^{\circ} \mathrm{C}\right)$ was achieved for cases not requiring aortic cross clamping, while lower core temperatures $\left(28-32^{\circ} \mathrm{C}\right)$ were achieved during aortic cross clamping. No cases required deep hypothermic arrest. In cases which required aortic crossclamping, cold $\left(<10^{\circ} \mathrm{C}\right)$ high potassium 8:1 blood cardioplegia solution (containing sodium bicarbonate, lidocaine, heparin, and potassium chloride) was delivered at 20 min intervals for myocardial protection. Modified ultrafiltration, with a pediatric hemoconcentrator (Terumo Cardiovascular Systems Corporation, Ann Arbor, MI) was performed during CPB in 19 of the 20 patients. A loading dose of heparin $(400 \mathrm{U} / \mathrm{kg}$ ) was administered intravenously and an activated clotting time (ACT) of $>400$ seconds (International Technidyne Corporation, Edison, NJ) was verified prior to the initiation of CPB. ACT's were measured every 30 minutes and were maintained $>400$ seconds during CPB. Heparin 
was neutralized with protamine in doses adjusted for the amount of circulating heparin and the patient's ACT at the end of CPB.

\section{Blood Sampling and Biochemical Assays}

Blood samples were obtained for measurement of ACE activity, bradykinin, PAI-1 antigen, t-PA antigen, D-dimer and inflammatory markers. Samples were collected at four time points: 1) after induction of anesthesia and prior to CPB (baseline), 2) following $30 \mathrm{~min}$ of $\mathrm{CPB}, 3$ ) upon arrival to the ICU (post CPB) and 4) at 9:00 on postoperative day 1 (POD1). All blood samples were taken from an indwelling arterial catheter.

\section{Fibrinolytic Markers}

All blood samples were collected on ice and centrifuged immediately at $0^{\circ} \mathrm{C}$ for 20 minutes. Plasma was then separated and stored at $-80^{\circ} \mathrm{C}$ until the time of assay. Blood for PAI- 1 and t-PA antigen assays was collected in vacutainer tubes containing acidified $0.105 \mathrm{M}$ sodium citrate (Biopool, Umea, Sweden). PAI-1 and t-PA antigen levels were determined using a 2site enzyme-linked immunosorbent assay (Immulyse, Biopool, Umea, Sweden). D-dimer levels were determined using enzyme-linked immunosorbent assay (TriniLIZE D-Dimer, Trinity Biotech, Jamestown, NY).

\section{Plasma Angiotensin-Converting Enzyme Activity and Bradykinin}

Serum ACE activity was determined by a three-step colorimetric assay in which ACE hydrolyzes the substrate p-hydroxybenzoyl-glycyl-L-histidyl-L-leucine and subsequent reactions lead to the formation of quinoneimine dye, which was measured spectrophotometrically (Fujirebio America Inc., Fairfield, NJ, U.S.A.). Blood for measurement of bradykinin was drawn into cold anhydrous ethanol and centrifuged after one hour; the supernatant was saved at $-80^{\circ} \mathrm{C}$ until the time of assay. Bradykinin concentration was determined using a commercially available enzyme immunoassay (Bachem, Peninsula Laboratories, Torrance, CA).

\section{Inflammatory Markers}

A panel of human inflammatory cytokines consisting of IL-1beta, IL-6, IL-8, IL-10, IL-12p70 and TNF- $a$ was simultaneously measured using the Human Inflammation Cytokine Cytometric Bead array kit (BD Biosciences Pharmingen, San Diego, CA, USA). The CBA assay uses the sensitivity of amplified fluorescence detection by flow cytometry to quantify soluble protein in a bead-based immunoassay. The kit includes a mixture of six inflammatory cytokine antibody specific precoated micro-bead populations, each with distinct fluorescent intensities.

\section{Clinical outcome data}

Although the study was designed only to look at biochemical markers of fibrinolysis and inflammation, we also collected clinical outcome data during the early postoperative period. These data collected included urine output, blood loss (chest tube drainage), blood products transfused, surgical re-exploration, time to extubation, need for postoperative ECMO, acute kidney injury (AKI) and 30-day mortality. AKI was defined using the serum creatinine $(\mathrm{SCr})$ criteria of the pediatric Risk Injury Failure Loss End-Stage $\left(\mathrm{pRIFLE}_{\mathrm{SCr}}\right)(16)$ kidney disease definition. Urine output AKI diagnosis criteria are unreliable in the operative and early postoperative period due to confounding by intravascular hypovolemia and diuretic administration. AKI "Risk" is defined as a SCr rise between 1.5 and <2 times baseline; "Injury" as a SCr rise between 2 and $<3$ times baseline; and "Failure" as a SCr rise 23 times baseline. The maximum SCr measurement obtained during ICU stay was divided by the 
baseline creatinine measurement to derive the highest pRIFLE ${ }_{S C r}$ score. All patients with a pRIFLE $_{\mathrm{SCr}}$ score of Risk or greater were classified as AKI patients.

\section{Statistical Analysis}

Data are presented as means \pm standard error of the mean (SEM) unless otherwise indicated. Categorical data were compared between groups using Chi-squared or Fischer's exact tests, as appropriate. Continuous baseline data were compared using Student's $t$-test or MannWhitney $U$ test, as appropriate. Correlations were determined using the Spearman's rho test. Sample size calculations were based on changes in POD1 PAI-1 concentrations using data from previously studied adult patients. We powered the study to detect a difference of 30ng/ $\mathrm{ml}$ in POD1 PAI-1 concentrations between the ACEi and no ACEi group, assuming a within group SD of $23 \mathrm{ng} / \mathrm{ml}$. The sample size per group needed to have $80 \%$ study power was 10 , with a 0.05 two-sided significance level. Comparison of the fibrinolytic response (PAI-1, t$\mathrm{PA}$ and D-dimer) between groups (ACEi vs No ACEi group) was made using a general linear model-repeated measures analysis of variance (ANOVA) in which the within patient variable was time and the between patient variables were ACE inhibition status, tertiles of CPB time and/or use of aminocaproic acid. Comparison of the inflammatory response (IL-6, IL-8 and IL-10) between groups (ACEi vs No ACEi group) was made using a general linear model-repeated measures ANOVA in which the within patient variable was time and the between patient variables were ACE inhibition status and use of cardioplegia (a surrogate marker for ischemia-reperfusion injury). Comparison of the inflammatory response between groups (AKI vs No AKI group) was made using a general linear model-repeated measures ANOVA in which the within patient variable was time and the between patient variables were AKI status, ACE inhibition status, tertiles of CPB time and surgical re-exploration. Biomarkers that were not normally distributed were log transformed prior to analysis. Estimated marginal means \pm SE derived from ANOVA were used to generate figures $2-4$. A 2-tailed $P$ value less than 0.05 was considered statistically significant. Statistical analyses were performed with the statistical package SPSS for Windows (Version 17.0, SPSS, Chicago, IL).

\section{Results}

\section{Pre-Randomization Patient Characteristics}

There were no significant differences between baseline subject characteristics of the two study groups with regard to age, gender, race, weight, mean arterial pressure (MAP), pulse pressure, heart rate, oxygen saturation, hematocrit, creatinine, potassium, single ventricle physiology, failure to thrive, ACEi dose, preoperative use of spironolactone, digoxin, enoxaparin or furosemide (Table 1). The preoperative platelet count was significantly lower in the ACEi group. The preoperative use of aspirin tended to be higher in the no ACEi group.

\section{Intra- and Postoperative Patient Characteristics}

MAP decreased significantly in all subjects after induction of anesthesia (from $71.8 \pm 2.9$ to $45.1 \pm 2.1 \mathrm{mmHg}$ pre-CPB; $\mathrm{F}=67.9, \mathrm{P}<0.001$ ) with no significant difference between the two study groups $(\mathrm{P}=0.2)$. There were no significant differences in CPB time, cross-clamp time, type of operation, use of aminocaproic acid or use of modified ultrafiltration between the two groups (Table 2). The use of cardioplegia tended to be higher in the ACEi group. Postoperative bleeding, blood products transfused, urine output, use of two or more inotropes on POD1, surgical re-exploration, use of ECMO, AKI and time to extubation were not significantly different between the two study groups. The total transfusion volume within the first 24 hours was $76.0 \pm 14.1 \mathrm{ml} / \mathrm{kg}$ in the No ACEi group compared to 
$132.3 \pm 34.6 \mathrm{ml} / \mathrm{kg}$ in the ACEi group $(\mathrm{P}=0.36)$. There were no venous thromboses in the postoperative period and no 30 -day mortality.

\section{Effect of ACE Inhibition on Baseline Biomarkers}

Baseline bradykinin concentrations were significantly higher and ACE activity significantly lower in the ACEi group compared to the no ACEi group ( $\mathrm{P}=0.04$ and $\mathrm{P}=0.001$ respectively; Figure 1). Bradykinin concentrations remained significantly higher at $30 \mathrm{~min}$ of $\mathrm{CPB}$ in the ACEi group as compared to the no ACEi group (20.1 \pm 5.3 vs $9.7 \pm 2.2 \mathrm{fmol} / \mathrm{ml}, \mathrm{P}=0.04)$. There were no significant differences in baseline concentrations of t-PA, PAI-1, D-dimer, IL-6, IL-8, or IL-10 between the two groups (Table 3).

\section{Fibrinolytic Response to CPB}

Figure 2 shows the effect of ACE inhibition on the t-PA (Panel A) and PAI-1 (Panel B) antigen responses during and after CPB. T-PA antigen concentrations increased significantly during the intraoperative period in both the ACEi group $(\mathrm{P}=0.01)$ and the no ACEi group $(\mathrm{P}=0.02)$, although the t-PA antigen response was not significantly different between the two groups $(\mathrm{P}=0.13)$. PAI-1 antigen increased 15 -fold following $\mathrm{CPB}$ and peaked on POD1 (from $4.6 \pm 1.2$ to $67.7 \pm 9.5 \mathrm{ng} / \mathrm{ml} ; \mathrm{P}<0.001$ for effect of time). POD1 PAI-1 antigen correlated significantly with $\mathrm{CPB}$ time $\left(\mathrm{r}^{2}=0.40, \mathrm{P}=0.03\right)$. While intraoperative PAI-1 antigen concentrations were similar between the two study groups ( $\mathrm{P}=0.5)$, POD1 PAI-1 antigen concentrations were significantly lower in the ACEi group compared to the no ACEi group $(\mathrm{P}=0.03$ ). $\mathrm{D}$-dimer concentrations increased significantly during $\mathrm{CPB}$ (from 56.1 \pm 8.4 at baseline to $166.3 \pm 24.7 \mathrm{ng} / \mathrm{ml}$ at $30 \mathrm{~min}$ of $\mathrm{CPB}, \mathrm{P}<0.001$ for effect of time) and peaked post-CPB $(422.2 \pm 120.9 \mathrm{ng} / \mathrm{ml})$. D-dimer concentrations were not significantly different between the two study groups $(\mathrm{P}=0.17)$.

\section{Inflammatory Response to CPB}

The pro-inflammatory markers IL-6 (from $1.9 \pm 1.0$ at baseline to a peak of $243.4 \pm 66.1 \mathrm{pg} / \mathrm{ml}$ on POD1), IL-8 (from 13.6 \pm 2.1 at baseline to a peak of $246.6 \pm 62.7 \mathrm{pg} / \mathrm{ml}$ post CPB) as well as the anti-inflammatory marker IL-10 (from $5.2 \pm 0.9$ at baseline to a peak of $430.3 \pm 93.5 \mathrm{pg}$ / $\mathrm{ml}$ post $\mathrm{CPB}$ ) increased significantly following $\mathrm{CPB}$ (all $\mathrm{P}<0.001$ for effect of time). There was no significant effect of ACE inhibition status on IL-6 concentrations during CPB $(\mathrm{P}=0.57)$, however IL-6 concentrations were significantly higher in the ACEi group following $\mathrm{CPB}$ ( $\mathrm{P}=0.02$; Figure 3 ). Although not significantly different, patients in the ACEi group were younger, had longer $\mathrm{CPB}$ times and received more transfusions. There was no significant difference in the IL- 6 response among the tertiles of age $(\mathrm{P}=0.63)$, tertiles of $\mathrm{CPB}$ time $(\mathrm{P}=0.64)$ or tertiles of total transfusion volume $(\mathrm{P}=0.68)$. Peak IL-6 concentrations on POD1 did not correlate with age $(\mathrm{P}=0.72)$, $\mathrm{CPB}$ time $(\mathrm{P}=0.49)$ of total transfusion volume $(\mathrm{P}=0.99)$. Furthermore, the postoperative IL-6 response remained significantly higher in the ACEi group, even after controlling for age, $\mathrm{CPB}$ time, total transfusion volume, use of aminocaproic acid or modified ultrafiltration in the model. Neither the IL-8 nor the IL-10 response were significantly different between the study groups $(\mathrm{P}=0.67$ and $\mathrm{P}=0.84$ respectively). In addition, IL-1, IL12p70 and TNFa did not increase significantly (all $\mathrm{P}>0.20$ ) and there were no significant differences between the ACEi and No ACEi group for any of these markers (all $\mathrm{P}>0.15$ ).

\section{Acute Kidney Injury and Inflammatory Response}

Because the use of ACEi in the perioperative period as well as an enhanced inflammatory response has been associated with an increased risk of postoperative AKI in some studies $(7,17,18)$, we compared the inflammatory response in patients who developed AKI to patients who did not. Forty-five percent (9/20) of patients developed AKI (Risk:5; Injury:2; 
Failure:2). No patients required hemodialysis. The IL-6 as well as the IL-8 response was significantly greater in patients who developed AKI compared to non-AKI patients $(\mathrm{P}=0.01$ and $\mathrm{P}=0.02$ for effect of AKI group respectively; Figure 4). The IL-6 response remained significantly higher among patients who developed AKI as compared to non-AKI patients even after controlling for $\mathrm{ACE}$ inhibition status ( $\mathrm{P}=0.01$ for effect of $\mathrm{AKI}$ group).

\section{Discussion}

This study examined the effect of preoperative ACE inhibition on the inflammatory and fibrinolytic response in children undergoing congenital cardiac surgery requiring CPB. Although ACE inhibition has been shown to blunt the increase in postoperative PAI-1 and IL-6 in adults, $(2,13,14)$ the effect of ACE inhibition on the PAI-1 and IL-6 response in children undergoing CPB is not known. The present study is the first to demonstrate that preoperative ACE inhibition attenuates the increase in postoperative PAI-1 while increasing IL-6 in children following CPB.

The fibrinolytic response to $\mathrm{CPB}$ is characterized by an initial hyperfibrinolytic phase that begins with a rapid rise in t-PA, plasmin, and D-dimer concentrations followed by a postoperative hypofibrinolytic (pro-thrombotic) phase associated with an increased PAI-1 secretion and decreased t-PA concentrations. In adults, PAI-1 levels begin to rise 2 hours after surgery, peak during the first 12-36 hours postoperatively and return to normal by the second postoperative day $(2,19)$. The activation of the fibrinolytic response during CPB in children was similar to that in adults with peak t-PA concentrations occurring during CPB, and peak PAI-1 concentrations occurring on POD1. ACE is strategically poised to control fibrinolytic balance by promoting the breakdown of bradykinin and the conversion of Ang I to Ang II. Ang II causes the release of PAI-1 thus inhibiting fibrinolysis $(8,20)$. Bradykinin stimulates t-PA release through $\mathrm{B}_{2}$ receptor agonism (21-23). ACE inhibition attenuated the increase in postoperative PAI- 1 concentrations in children, consistent with previous reports in adults (2). While bradykinin concentrations were higher in the ACEi group, the t-PA antigen response was not significantly different between the two groups. Although not measured in the present study, differential thrombin formation (a potent stimulus for t-PA release (24)) between the two study groups may explain the t-PA antigen response in our study population.

$\mathrm{CPB}$ caused a profound activation of the inflammatory response in our pediatric study population, as consistent with previous reports $(3,7,25)$. Because excessive activation of the inflammatory response following CPB in children is associated with increased morbidity (kidney injury, prolonged mechanical ventilation, and increased length of stay), $(7,25)$ attenuating the inflammatory response could potentially improve outcomes. Various interventions have been shown to attenuate the inflammatory response including preoperative administration of steroids, modified ultrafiltration and aminocaproic acid $(26,27)$. The effect of ACE inhibition on the postoperative inflammatory response following CPB is uncertain. In addition, no prior studies have evaluated the effect of ACE inhibition on the postoperative inflammatory response in children. In adults, most studies suggest that preoperative ACE inhibition attenuates the pro-inflammatory response following CPB, whereas other studies found no effect $(13-15,28)$. The anti-inflammatory finding observed in some of the adults studies may be confounded by non-randomized study design (13), concomitant use of statins (14) or inclusion of the IL-6 -174 G/C polymorphism (28).

Surprisingly, ACE inhibition enhanced the postoperative IL-6 response in children. The present study does not specifically address the mechanism for this effect. While ACE inhibition decreases Ang II formation (a stimulus for IL-6 expression (9)), it also increases bradykinin concentrations (a stimulus for IL-6 expression (11)). The net effect on IL-6 
expression may depend on the balance between circulating Ang II and bradykinin concentrations. Although Ang II concentrations were not measured, bradykinin concentrations were significantly higher at baseline and during CPB in the ACEi group. Thus, it is plausible that ACE inhibition decreases PAI-1 expression (decreased Ang II) while simultaneously increasing IL-6 expression (increased bradykinin effects dominate decreased Ang II effects) in patients undergoing CPB. Also, the effect of ACE inhibition on the postoperative IL- 6 response remained significant even after controlling for potential confounding factors such as age, CPB time and total transfusion volume.

\section{Study Limitations}

While patients were randomized to preoperative ACE inhibition, the present study was neither blinded nor placebo-controlled. However, the dose and type of ACE inhibitor (all patients received enalapril prior to randomization) were similar between the two study groups. Furthermore, stopping ACEi therapy 72 hours prior to surgery was sufficient time to restore plasma ACE activity to normal levels. This is a small study and provides pilot data concerning the effects of ACE inhibition in the pediatric patient undergoing $\mathrm{CPB}$ and does not suggest a change in current practice. However, in a randomized clinical trial enalapril did not improve somatic growth, ventricular function, or heart failure severity in infants with single-ventricle physiology in the first year of life, bringing into question the routine use of enalapril in this population (29).

This study was not designed to assess the effect of ACE inhibition status on risk of postoperative AKI in children. Retrospective studies in adults undergoing cardiac surgery suggest that preoperative ACE inhibition increases the risk of postoperative AKI between 27 and $70 \%(17,18)$ while other studies suggest ACE inhibition decreases AKI risk (30). Our finding that early inflammation precedes AKI diagnosis suggests that inflammation contributes to AKI following cardiac surgery. Although more patients who developed AKI in the present study had been randomized to continuation of ACEi, a larger adequately powered prospective study designed with $\mathrm{AKI}$ as the primary outcome is necessary to determine the effect of ACE inhibition on postoperative AKI.

In conclusion, this study demonstrates that ACE inhibition decreases postoperative PAI-1 concentrations (increases propensity for fibrinolysis) while enhancing IL-6 concentrations in children following CPB. Bleeding and transfusion requirements were not significantly increased despite the decrease in PAI-1 concentrations. Although IL-6 concentrations were also significantly increased in patients who developed AKI, ACE inhibition was not associated with an increased risk of postoperative AKI, most likely because this study was underpowered to detect an effect of ACE inhibition on the risk of postoperative AKI. The results of this study do not suggest that ACEi should be stopped prior to surgery but do raise important questions about the use of ACEi, inflammation, and AKI in children undergoing CPB. Future studies are needed to determine the impact of ACE inhibition status and inflammatory response on the risk of developing AKI in children undergoing CPB.

\section{Acknowledgments}

Funding Sources: This research was funded by the NIH [HL085740] and supported in part by Vanderbilt CTSA [Grant 1 UL1 RR024975] from the National Center for Research Resources, NIH.

We would like to thank Jeff Petro for his technical assistance. 


\section{References}

1. Manrique A, Jooste EH, Kuch BA, et al. The association of renal dysfunction and the use of aprotinin in patients undergoing congenital cardiac surgery requiring cardiopulmonary bypass. Anesth Analg. 2009; 109:45-52. [PubMed: 19535694]

2. Pretorius M, Murphey LJ, McFarlane JA, et al. Angiotensin-converting enzyme inhibition alters the fibrinolytic response to cardiopulmonary bypass. Circulation. 2003; 108:3079-3083. [PubMed: 14656921]

3. Chew MS, Brandslund I, Brix-Christensen V, et al. Tissue injury and the inflammatory response to pediatric cardiac surgery with cardiopulmonary bypass: A descriptive study. Anesthesiology. 2001; 94:745-753. discussion 745A. [PubMed: 11388523]

4. Hunt BJ, Parratt RN, Segal HC, et al. Activation of coagulation and fibrinolysis during cardiothoracic operations. Ann Thorac Surg. 1998; 65:712-718. [PubMed: 9527200]

5. Rifon J, Paramo JA, Panizo C, et al. The increase of plasminogen activator inhibitor activity is associated with graft occlusion in patients undergoing aorto-coronary bypass surgery. $\mathrm{Br} \mathrm{J}$ Haematol. 1997; 99:262-267. [PubMed: 9375736]

6. Petaja J, Peltola K, Sairanen H, et al. Fibrinolysis, antithrombin iii, and protein c in neonates during cardiac operations. Journal of Thoracic \& Cardiovascular Surgery. 1996; 112:665-671. [PubMed: 8800154]

7. Liu KD, Altmann C, Smits G, et al. Serum interleukin-6 and interleukin-8 are early biomarkers of acute kidney injury and predict prolonged mechanical ventilation in children undergoing cardiac surgery: A case-control study. Crit Care. 2009; 13:R104. [PubMed: 19570208]

8. Vaughan DE, Lazos SA, Tong K. Angiotensin ii regulates the expression of plasminogen activator inhibitor-1 in cultured endothelial cells. A potential link between the renin-angiotensin system and thrombosis. J Clin Invest. 1995; 95:995-1001. [PubMed: 7884001]

9. Han Y, Runge MS, Brasier AR. Angiotensin ii induces interleukin-6 transcription in vascular smooth muscle cells through pleiotropic activation of nuclear factor-kappa $b$ transcription factors. Circ Res. 1999; 84:695-703. [PubMed: 10189357]

10. Emeis JJ. Perfused rat hindlegs. A model to study plasminogen activator release. Thromb Res. 1983; 30:195-203. [PubMed: 6683431]

11. Huang CD, Tliba O, Panettieri RA Jr, et al. Bradykinin induces interleukin-6 production in human airway smooth muscle cells: Modulation by th2 cytokines and dexamethasone. Am J Respir Cell Mol Biol. 2003; 28:330-338. [PubMed: 12594059]

12. Vandekerckhove F, Opdenakker G, Van Ranst M, et al. Bradykinin induces interleukin- 6 and synergizes with interleukin-1. Lymphokine Cytokine Res. 1991; 10:285-289. [PubMed: 1932373]

13. Brull DJ, Sanders J, Rumley A, et al. Impact of angiotensin converting enzyme inhibition on postcoronary artery bypass interleukin 6 release. Heart. 2002; 87:252-255. [PubMed: 11847165]

14. Radaelli A, Loardi C, Cazzaniga M, et al. Inflammatory activation during coronary artery surgery and its dose-dependent modulation by statin/ace-inhibitor combination. Arterioscler Thromb Vasc Biol. 2007; 27:2750-2755. [PubMed: 17823365]

15. Kwapisz MM, Muller M, Schindler E, et al. The effect of intravenous quinaprilat on plasma cytokines and hemodynamic variables during cardiac surgery. J Cardiothorac Vasc Anesth. 2004; 18:53-58. [PubMed: 14973800]

16. Zappitelli M, Bernier P-L, Saczkowski RS, et al. A small post-operative rise in serum creatinine predicts acute kidney injury in children undergoing cardiac surgery. Kidney Int. 2009; 76:885892. [PubMed: 19641482]

17. Miceli A, Capoun R, Fino C, et al. Effects of angiotensin-converting enzyme inhibitor therapy on clinical outcome in patients undergoing coronary artery bypass grafting. J Am Coll Cardiol. 2009; 54:1178-1184.

18. Arora P, Rajagopalam S, Ranjan R, et al. Preoperative use of angiotensin-converting enzyme inhibitors/angiotensin receptor blockers is associated with increased risk for acute kidney injury after cardiovascular surgery. Clin J Am Soc Nephrol. 2008; 3:1266-1273. [PubMed: 18667735]

19. Chandler WL, Fitch JC, Wall MH, et al. Individual variations in the fibrinolytic response during and after cardiopulmonary bypass. Thromb Haemost. 1995; 74:1293-1297. [PubMed: 8607112] 
20. Ridker PM, Gaboury CL, Conlin PR, et al. Stimulation of plasminogen activator inhibitor in vivo by infusion of angiotensin ii. Evidence of a potential interaction between the renin-angiotensin system and fibrinolytic function. Circulation. 1993; 87:1969-1973. [PubMed: 8504511]

21. Pretorius M, Rosenbaum D, Vaughan DE, et al. Angiotensin-converting enzyme inhibition increases human vascular tissue-type plasminogen activator release through endogenous bradykinin. Circulation. 2003; 107:579-585. [PubMed: 12566370]

22. Brown NJ, Gainer JV, Murphey LJ, et al. Bradykinin stimulates tissue plasminogen activator release from human forearm vasculature through b2 receptor-dependent, no synthase-independent, and cyclooxygenase-independent pathway. Circulation. 2000; 102:2190-2196. [PubMed: 11056091]

23. Witherow FN, Dawson P, Ludlam CA, et al. Bradykinin receptor antagonism and endothelial tissue plasminogen activator release in humans. Arterioscler Thromb Vasc Biol. 2003; 23:16671670. [PubMed: 12869356]

24. Muldowney JA 3rd, Painter CA, Sanders-Bush E, et al. Acute tissue-type plasminogen activator release in human microvascular endothelial cells: The roles of galphaq, plc-beta, ip3 and 5,6epoxyeicosatrienoic acid. Thromb Haemost. 2007; 97:263-271. [PubMed: 17264956]

25. Appachi E, Mossad E, Mee RB, et al. Perioperative serum interleukins in neonates with hypoplastic left-heart syndrome and transposition of the great arteries. J Cardiothorac Vasc Anesth. 2007; 21:184-190. [PubMed: 17418729]

26. Kozik DJ, Tweddell JS. Characterizing the inflammatory response to cardiopulmonary bypass in children. Ann Thorac Surg. 2006; 81:S2347-2354. [PubMed: 16731102]

27. Greilich PE, Brouse CF, Whitten CW, et al. Antifibrinolytic therapy during cardiopulmonary bypass reduces proinflammatory cytokine levels: A randomized, double-blind, placebo-controlled study of epsilon-aminocaproic acid and aprotinin. J Thorac Cardiovasc Surg. 2003; 126:14981503. [PubMed: 14666025]

28. Trevelyan J, Brull DJ, Needham EWA, et al. Effect of enalapril and losartan on cytokines in patients with stable angina pectoris awaiting coronary artery bypass grafting and their interaction with polymorphisms in the interleukin-6 gene. Am J Cardiol. 2004; 94:564-569. [PubMed: 15342284]

29. Hsu DT, Zak V, Mahony L, et al. Enalapril in infants with single ventricle: Results of a multicenter randomized trial. Circulation. 2010; 122:333-340. [PubMed: 20625111]

30. Benedetto U, Sciarretta S, Roscitano A, et al. Preoperative angiotensin-converting enzyme inhibitors and acute kidney injury after coronary artery bypass grafting. Ann Thorac Surg. 2008; 86:1160-1165. [PubMed: 18805152] 

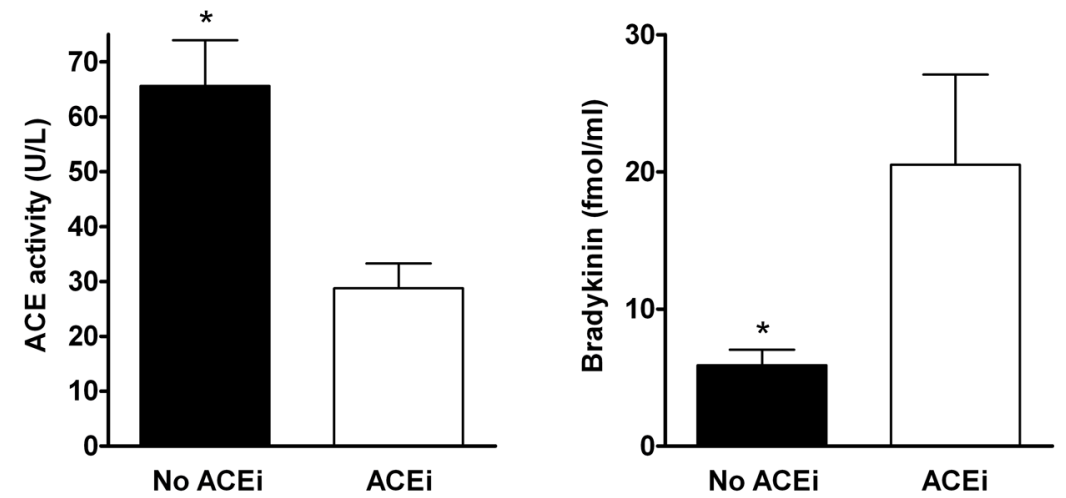

${ }^{*} \mathrm{P}<0.05$ versus $\mathrm{ACE}$ i group

Figure 1.

Baseline angiotensin-converting enzyme (ACE) activity and bradykinin concentrations in patients randomized to cessation or continuation of ACE(i) inhibitor use 72 hours prior to surgery. ${ }^{*} \mathrm{P}<0.05$ versus No ACEi group. 

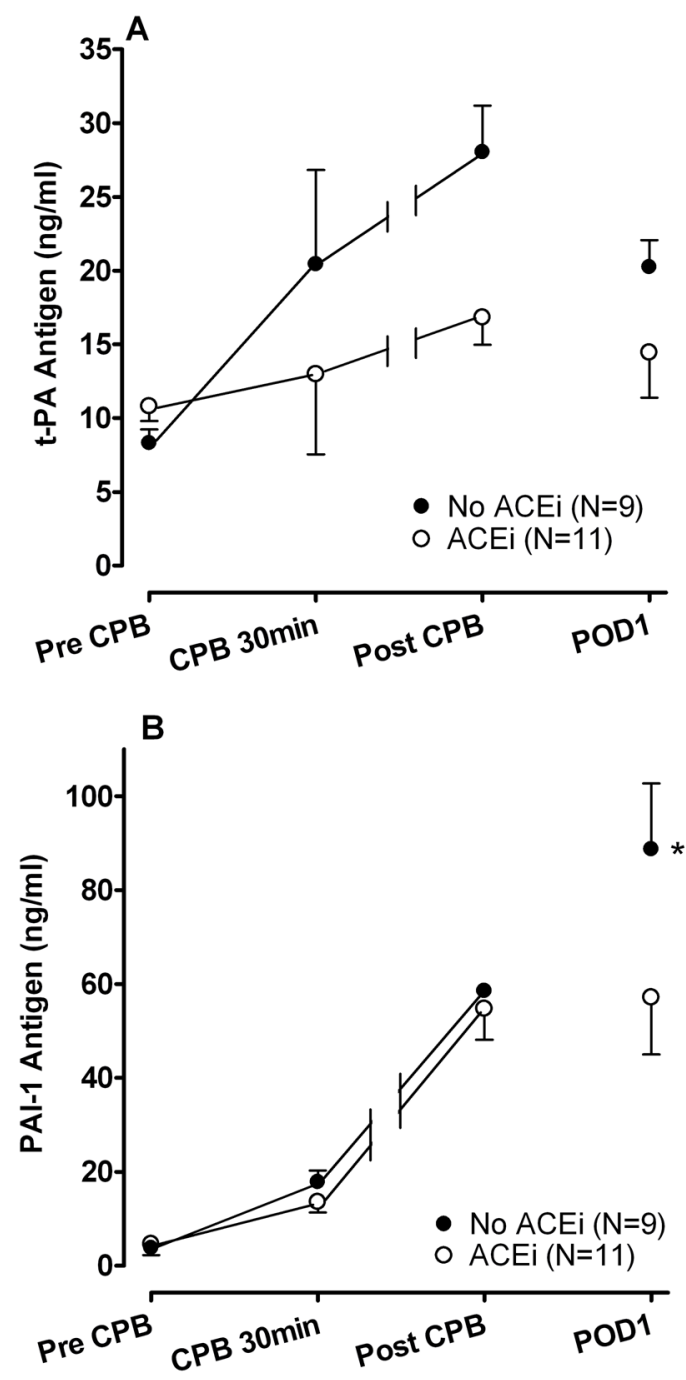

Figure 2.

Estimated marginal means \pm SE (A) tissue-type plasminogen activator (t-PA) antigen and (B) plasminogen activator inhibitor-1 (PAI-1) antigen concentrations during and after cardiopulmonary bypass (CPB). Postoperative day 1 (POD1) PAI-1 antigen concentrations were significantly lower in the angiotensin-converting enzyme inhibitor (ACEi) group compared to the No ACEi group. ${ }^{*} \mathrm{P}=0.03$ versus ACEi group. 


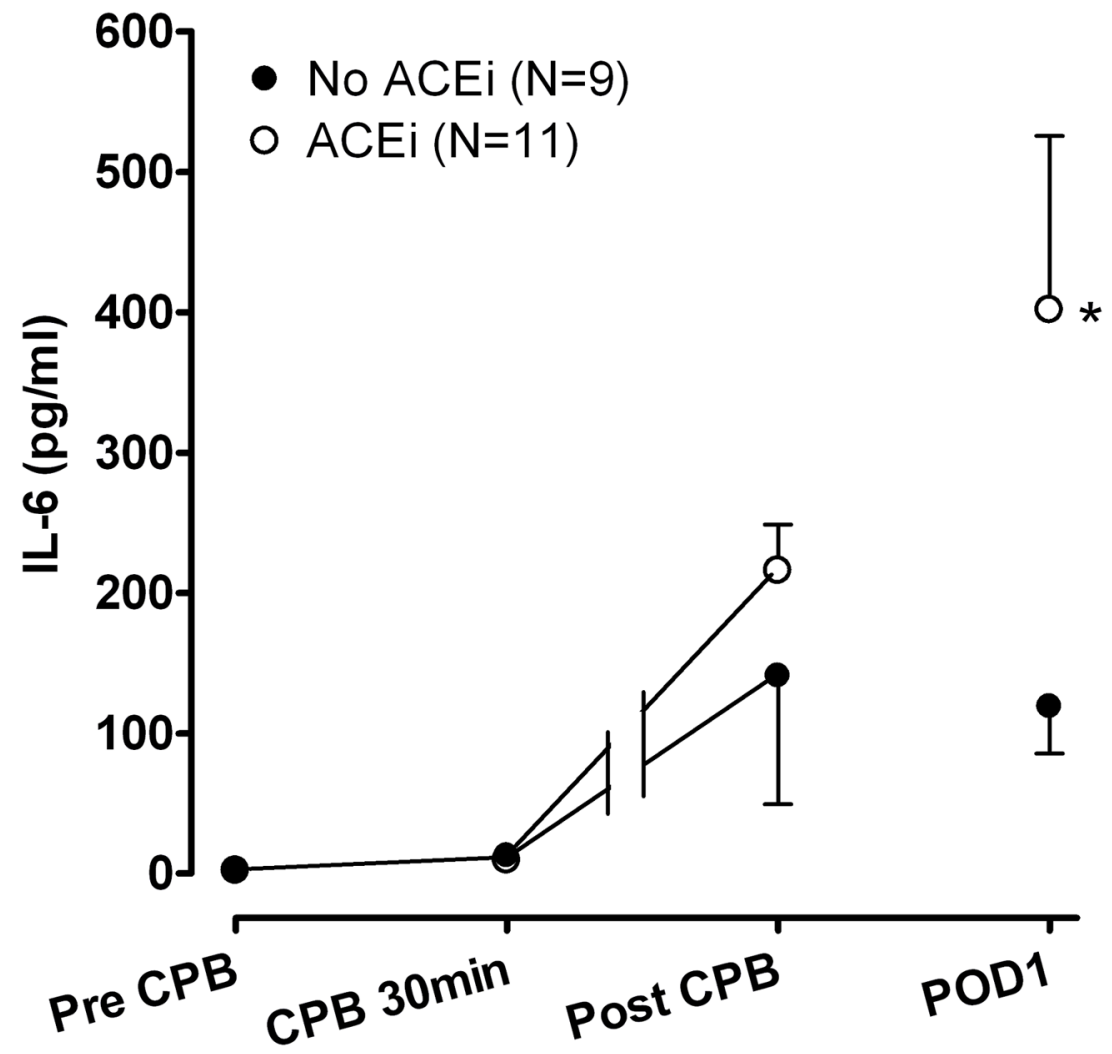

Figure 3.

Estimated marginal means \pm SE interleukin (IL)-6 concentrations during and after cardiopulmonary bypass (CPB). IL-6 concentrations were significantly higher in the angiotensin-converting enzyme inhibitor (ACEi) group following CPB. POD1 indicates postoperative day 1. $* \mathrm{P}=0.04$ versus No ACEi group. 

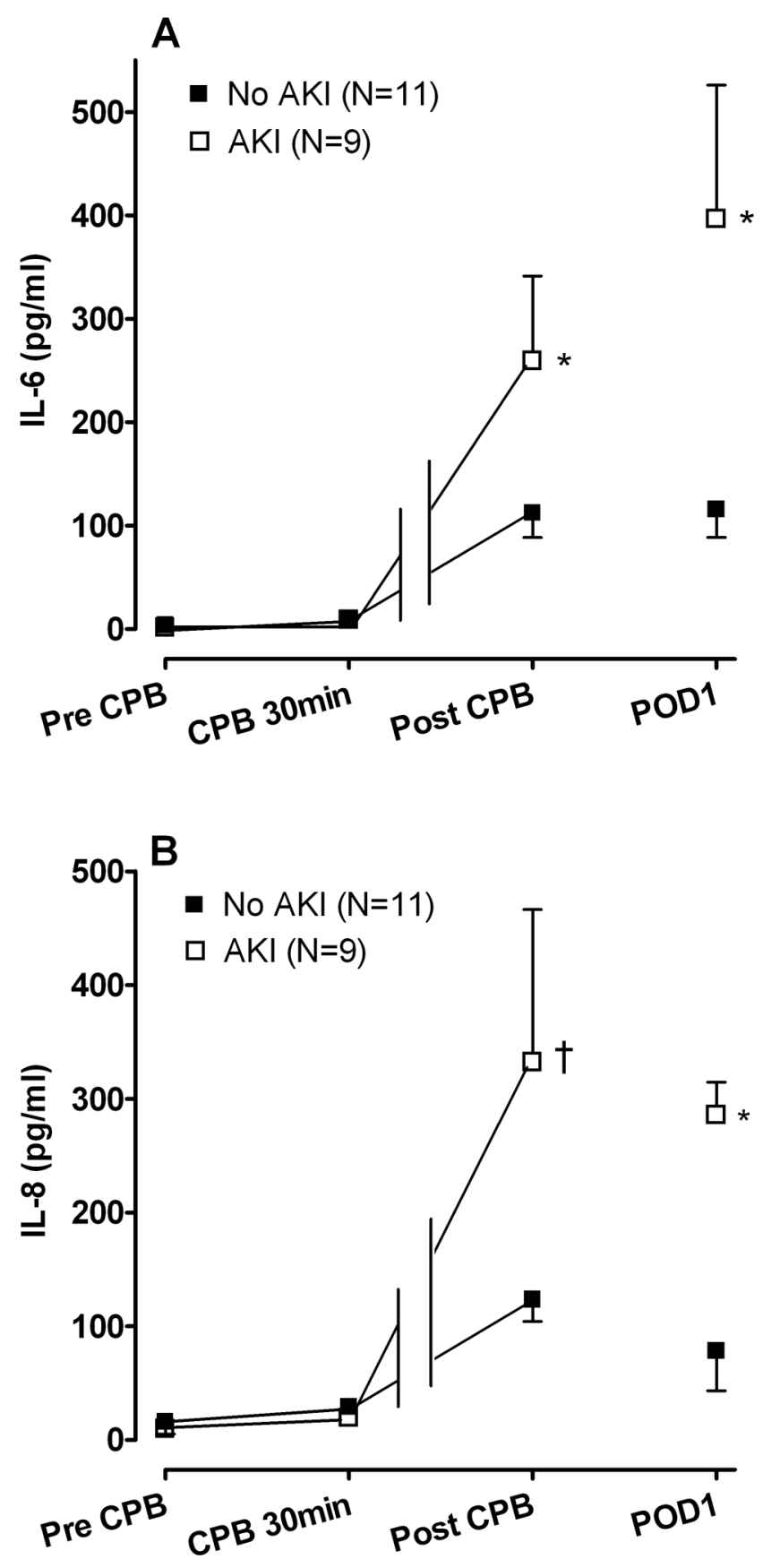

Figure 4.

Estimated marginal means \pm SE (A) interleukin (IL)-6 and (B) IL-8 concentrations in patients who did and did not develop postoperative acute kidney injury (AKI). The IL-6 as well as the IL-8 concentrations was significantly greater in the AKI group compared to the No AKI group $\left(\mathrm{P}=0.01\right.$ and $\mathrm{P}=0.02$ respectively). ${ }^{*} \mathrm{P}<0.01, \dagger \mathrm{P}<0.05$ versus No AKI group. CPB indicates cardiopulmonary bypass, POD1 indicates postoperative day 1. 
Table 1

Pre-Randomization Patient Characteristics

\begin{tabular}{|c|c|c|}
\hline & No ACE-Inhibitor (N=9) & ACE-Inhibitor $(\mathrm{N}=11)$ \\
\hline Age (months) & $20.8 \pm 6.5$ & $13.7 \pm 3.5$ \\
\hline Gender, Male, $N(\%)$ & $6(66.7)$ & $7(63.6)$ \\
\hline Race, Caucasian, N(\%) & $7(77.8)$ & $9(81.8)$ \\
\hline Weight (kg) & $9.1 \pm 1.2$ & $7.8 \pm 1.2$ \\
\hline Weight (percentile for age) & $11.7 \pm 5.8$ & $20.2 \pm 8.4$ \\
\hline Mean arterial pressure $(\mathrm{mmHg})$ & $74.4 \pm 4.6$ & $69.5 \pm 3.8$ \\
\hline Pulse pressure (mmHg) & $43.7 \pm 3.2$ & $40.9 \pm 3.6$ \\
\hline Heart Rate (BPM) & $123.1 \pm 5.9$ & $125.9 \pm 3.1$ \\
\hline Pulse oximetry saturation (\%) & $82.8 \pm 2.5$ & $85.2 \pm 2.3$ \\
\hline Hematocrit (\%) & $45.3 \pm 0.8$ & $44.7 \pm 2.3$ \\
\hline Platelet count $(\mathrm{k} / \mu \mathrm{l})$ & $397.8 \pm 24.7$ & $317.2 \pm 14.9^{*}$ \\
\hline Creatinine (mg/dl) & $0.41 \pm 0.02$ & $0.43 \pm 0.04$ \\
\hline Potassium (meq/L) & $4.7 \pm 0.2$ & $4.6 \pm 0.2$ \\
\hline Single ventricle physiology, $\mathrm{N}(\%)$ & $9(100)$ & $8(72.7)$ \\
\hline Failure to Thrive, $\mathrm{N}(\%)$ & $4(44.4)$ & $6(54.5)$ \\
\hline ACE Inhibitor Dose (mg/kg/day) & $0.25 \pm 0.04$ & $0.24 \pm 0.03$ \\
\hline \multicolumn{3}{|l|}{ Other Preoperative Medications } \\
\hline Aspirin, N (\%) & $9(100)$ & $7(63.6)^{\dagger}$ \\
\hline Spironolactone, N (\%) & $3(33.3)$ & $2(18.2)$ \\
\hline Digoxin, N (\%) & $5(55.6)$ & $4(36.4)$ \\
\hline Enoxaparin, $\mathrm{N}(\%)$ & $2(22.2)$ & $1(9.1)$ \\
\hline Furosemide, $\mathrm{N}(\%)$ & $7(77.8)$ & $8(72.7)$ \\
\hline $\begin{array}{l}\text { ACE indicates angiotensin convertin } \\
\mathrm{P}<0.05 \text {, }\end{array}$ & enzyme. & \\
\hline
\end{tabular}


Table 2

Intraoperative and Postoperative Patient Characteristics

\begin{tabular}{|c|c|c|c|}
\hline & No ACE-Inhibitor (N=9) & ACE-Inhibitor (N=11) & P-value \\
\hline CPB time (min) & $113.7 \pm 23.9$ & $138.4 \pm 19.5$ & 0.43 \\
\hline Cross-clamp time (min) & $23.7 \pm 12.2$ & $64.6 \pm 21.8$ & 0.26 \\
\hline Cardioplegia, $\mathrm{N}(\%)$ & $3(33.3)$ & $8(72.7)$ & 0.18 \\
\hline Operation, $\mathrm{N}(\%)$ & & & 0.70 \\
\hline Fontan & $4(44.4)$ & $4(36.4)$ & \\
\hline Bidirectional Glenn & $4(44.4)$ & $3(27.3)$ & \\
\hline VSD or AVSD & 0 & $2(18.2)$ & \\
\hline Mitral valve Replacement & 0 & $1(9.1)$ & \\
\hline Other & $1(11.1)$ & $1(9.1)$ & \\
\hline Aminocaproic Acid, N(\%) & $4(44.4)$ & $5(45.5)$ & 1.0 \\
\hline Modified Ultrafiltration, $\mathrm{N}(\%)$ & $9(100)$ & $10(90.9)$ & 1.0 \\
\hline Chest tube output in $4 \mathrm{hrs}(\mathrm{ml} / \mathrm{kg})$ & $19.8 \pm 2.9$ & $38.4 \pm 13.8$ & 0.94 \\
\hline Chest tube output in $24 \mathrm{hrs}(\mathrm{ml} / \mathrm{kg})$ & $43.2 \pm 6.2$ & $76.3 \pm 20.7$ & 0.47 \\
\hline \multicolumn{4}{|l|}{ Transfusions in $1^{\text {st }} 24$ hours $(\mathrm{ml} / \mathrm{kg})$} \\
\hline Packed red blood cells & $37.0 \pm 8.1$ & $69.1 \pm 18.4$ & 0.38 \\
\hline Platelets & $22.0 \pm 3.7$ & $26.1 \pm 6.9$ & 0.68 \\
\hline Cryoprecipitate & $2.9 \pm 1.3$ & $6.9 \pm 2.5$ & 0.29 \\
\hline Fresh Frozen Plasma & $16.1 \pm 4.4$ & $30.2 \pm 11.1$ & 0.80 \\
\hline \multicolumn{4}{|l|}{ Urine output (ml/kg) } \\
\hline Intraoperative & $8.9 \pm 1.8$ & $9.3 \pm 2.4$ & 0.86 \\
\hline First 24 hours & $57.8 \pm 13.4$ & $55.7 \pm 9.3$ & 0.72 \\
\hline Two or more inotropes on POD1, N(\%) & $3(33.3)$ & $4(36.4)$ & 1.0 \\
\hline Surgical re-exploration, $\mathrm{N}(\%)$ & $2(22.2)$ & $3(27.3)$ & 1.0 \\
\hline Time to extubation (hours) & $36.4 \pm 18.7$ & $89.2 \pm 30.1$ & 0.32 \\
\hline Postoperative ECMO, N(\%) & 0 & $1(9.1)$ & 1.0 \\
\hline Acute Kidney Injury, N(\%) & $3(33.3)$ & $6(54.5)$ & 0.41 \\
\hline
\end{tabular}

CPB, cardiopulmonary bypass; VSD, ventricular septal defect; AVSD, atrial ventricular septal defect; POD1, postoperative day 1; ECMO, extracorporeal membrane oxygenation. 
Table 3

Preoperative Biomarkers

\begin{tabular}{lccc}
\hline & No ACE-Inhibitor (N=9) & ACE-Inhibitor (N=11) & P-value \\
\hline t-PA antigen (ng/ml) & $8.2 \pm 0.9$ & $9.5 \pm 2.2$ & 0.59 \\
PAI-1 antigen (ng/ml) & $3.2 \pm 0.9$ & $5.8 \pm 2.1$ & 0.73 \\
D-dimer (ng/ml) & $66.9 \pm 14.2$ & $47.2 \pm 9.7$ & 0.31 \\
IL-6 (pg/ml) & $2.7 \pm 1.6$ & $1.3 \pm 1.3$ & 0.25 \\
IL-8 (pg/ml) & $16.0 \pm 4.0$ & $11.7 \pm 2.1$ & 0.59 \\
IL-10 (pg/ml) & $5.0 \pm 1.5$ & $5.4 \pm 1.3$ & 0.73 \\
\hline
\end{tabular}

t-PA, tissue-type plasminogen activator; PAI-1, plasminogen activator inhibitor-1; IL, interleukin. 